\title{
DE LA FASCINACIÓN AL REALISMO: REFLEXIONES SOBRE EL USO DE LAS CARTAS PRIVADAS PARA EL ESTUDIO DE LA EMIGRACIÓN DESDE EL CASO VASCO
}

Óscar Álvarez Gila

Center for Basque Studies. University of Nevada, Reno

Euskal Herriko Unibertsitatea 



\section{INTRODUCCIÓN ${ }^{1}$}

Toda renovación historiográfica, ya sea metodológica o epistemológica, suele venir por lo general aderezada de una cierta aura salvífica, con el ánimo declarado de redimir a la ciencia histórica de sus errores y apartarla de unas vías que se entienden agotadas y estériles, para hacer progresar el conocimiento científico del pasado mediante innovadoras perspectivas y caminos nunca antes hollados. Cierto es que esto último no pasa de ser una mera utopía, pues a estas alturas de la historia, y sin caer erróneamente en el otrora tan aceptado principio de que, en cuestiones de conocimiento, no somos sino "enanos subidos a hombros de gigantes", es bien sabido que ha existido a lo largo de los últimos siglos un amplio elenco de buenos historiadores que han llegado a alumbrar, en un momento u otro de su carrera, ideas geniales sobre las que se han sentado las bases de renovaciones historiográficas acaecidas mucho tiempo después de que ellos mismos fueran ya "lágrimas en la lluvia". ${ }^{2}$ No obstante, los mejores licores suelen derivarse de la decantación de viejos caldos; y, de este modo, los sucesivos retornos que ha experimentado la Historia en las últimas décadas (el retorno del sujeto, el retorno de la historia narrativa, el retorno de la biografía, el retorno de la historia política) no han significado en ningún caso una mera vuelta al pasado, sino una reinterpretación de antiguas aproximaciones metodológicas a la luz de los avances más recientes de la historiografía.

El uso de las fuentes personales para el conocimiento del pasado ha vivido también, como otras "nuevas historias", su particular proceso de epifanía, labo-

\footnotetext{
${ }^{1}$ Agradezco los comentarios y correcciones a este texto de Alberto Angulo Morales, Jon Ander Ramos Martínez, Eneko Sanz Goikoetxea, Matteo Manfredi y Virginia López de Maturana Diéguez (Universidad del País Vasco); y a Matteo Sanfilippo (Università degli Studi della Tuscia).

${ }^{2}$ Como declaraba el replicante Roy Batty en su aguda reflexión ante el paso inexorable del tiempo: "todos estos momentos se perderán en el tiempo como lágrimas en la lluvia" (Blade Runner, de Ridley Scott, 1982).
} 
rioso ascenso y gloria en los altares de la historiografía. Hemos de comenzar aclarando que dentro de dicho concepto de "fuentes personales", en el contexto en el que estamos, se suelen incluir comúnmente todos aquellos documentos, tanto escritos como orales o incluso iconográficos, que han sido generados, no por la acción de instituciones políticas, corporaciones económicas o personajes de gran relevancia histórica, sino por personas comunes y corrientes. De hecho, las fuentes personales ya contaban con una larga tradición de uso en la historiografía clásica, por lo que la renovación no vino tanto de la mano del uso de una fuente inédita, como de un cambio en el foco hacia el que se dirigía la mirada. Los grandes personajes daban paso ahora a los hombres y mujeres del común. No se trataba, por tanto, de documentos que hablasen de la "alta historia" de la vida política y económica ni de los aportes de los "grandes genios", sino de las vidas anónimas de personas cuya trascendencia, en el tiempo que les tocó vivir, apenas sobrepasó el círculo de sus familias, amistades y comunidades locales.

Había, ciertamente, mucho de ideología entre los pioneros de esta nueva forma de entender la historia, algo que quizá hoy pueda parecernos fuera de lugar, pero que era hasta cierto punto comprensible en su momento. El uso de las fuentes personales, y muy especialmente de la fuente oral, se hallaba teñido de un fuerte carácter reivindicativo. Cartas, memorias, fotografías y entrevistas grabadas constituían, en la consideración de quienes abogaban por su uso, un nuevo frente de batalla en el combate por democratizar la historia y otorgar "voz a los sin-voz" frente a la tradicional elitización que a su entender caracterizaba a dicha ciencia. El trasfondo ideológico de tales interpretaciones resultaba innegable y fue a la vez el motor de ascenso pero también el freno a la expansión del uso de estas nuevas fuentes: mientras el más militante de sus adeptos llegaba incluso al extremo de considerar que sólo las fuentes personales eran "la verdad de la historia", ${ }^{3}$ por otro lado el historiador tradicional acogía con horrorizada

${ }^{3}$ La historia basada en fuentes personales, y muy especialmente la historia oral, se presentaba como una historia reivindicativa en la que, más allá de los principios y cautelas propias del saber científico (la crítica externa e interna de la documentación), el historiador se rendía ante una fuente que adquiría un fuerte sentido teleológico: la fuente personal era la verdad. Como bien resume Jorge Iván Vergara: "Quienes utilizan los testimonios tienden a creer que éstos son una expresión directa y no mediada de las representaciones y modos de sentir y pensar del pueblo, sus mujeres, etc. Se emplea a menudo una metáfora para ilustrar esta tesis: la voz del pueblo" (Vergara 2004). 
prevención el componente reivindicativo que, por lo general, se escondía detrás de todo aquel que osaba citar, en sus artículos, libros o comunicaciones a congresos, cualquiera de estas nuevas piezas documentales.

Con el paso del tiempo, las aguas se han serenado y los acalorados debates y encendidas proclamas de otros tipos han dado paso a un agradable aburrimiento. ${ }^{4}$ Limadas las iniciales expectativas epistemológicas e ideológicas generadas en torno a la documentación personal, su uso se ha vuelto convencional, desapareciendo progresivamente cualquier nota calificativa - ya fuera peyorativa o elogiosa - sobre su utilización. Hoy en día nadie se atreve a descalificar abiertamente a priori una investigación por estar basada en fuentes orales, por poner un ejemplo, como era habitual hace apenas dos décadas; como tampoco son ya muchos los que persisten en buscar en dichos documentos otra cosa que no sea lo mismo que se busca en cualquier otro tipo de fuente que contribuya a ampliar el conocimiento y enriquecer el discurso sobre el pasado. ${ }^{5}$ Estamos en un buen momento, por lo tanto, para esbozar alguna reflexión sobre lo que hemos ganado, o perdido, con su uso.

Partiendo de esta base, nuestra intención en estas páginas no es, por lo tanto, presentar un estudio de caso basado en documentación personal, ni tampoco elaborar un estudio bibliográfico exhaustivo de la historiografía publicada hasta el momento sobre el uso de las fuentes personales, y más en concreto de la documentación epistolar privada, en su aplicación para el estudio de las migraciones. Aunque haremos algún escarceo bibliográfico en este recorrido, no pretenderemos por lo tanto profundizar en un análisis sistemático de todos los aportes, tanto exitosos como fallidos — que los hay y no son escasos- de

\footnotetext{
${ }^{4}$ Sobre la situación de la historia oral en España, cfr. Borderías (1995). En Latinoamérica la situación es diferente. En 2005 Liliana Barela, en su comunicación "Aspectos teóricos del trabajo de Historia Oral en los barrios", expuesta en el Encuentro Internacional de Historia Oral "Oralidad y Archivos de la Memoria" (Colombia, 5-7 de mayo), afirmaba aún que existen "por un lado, la historia oral militante", radicalmente alternativa, y por otro, una historia oral académica. "La primera tiene la ambición de hacer la historia desde abajo y desde el punto de vista de los excluidos; intervenir, interpretar, tomar distancia, como lo hacen los historiadores es casi un sacrilegio y una apropiación ilegítima de poder". Esta autora sigue siendo de las que manifiestan que "quienes hacemos historia oral pretendemos ser "la voz de los que no tienen voz".

5 "Afortunadamente, después de casi medio siglo de practicar la entrevista grabada, empezamos a poder hablar de Historia Oral Tradicional; por fin podemos quitamos un enorme peso de encima ya que no necesitamos ser pioneros ni blasonar infantilmente de vanguardia ninguna" (Vilanova 1998: 65-66).
} 
la historiografía precedente, en lo relativo a la cuestión que nos ocupa. De hecho, existen ya sobre este particular algunos excelentes trabajos a este respecto, ${ }^{6}$ que pueden servir todavía de referencia muy válida para el conocimiento de la historiografía hispana sobre migraciones - y por lo tanto, también sobre el uso de documentos personales_- y sobre los que sería redundante cualquier apreciación que aquí hagamos.

\section{LA BIBLIOGRAFÍA}

En todo caso resulta necesario, a fin de situarnos en el contexto adecuado, partir de una somera presentación bibliográfica sobre la evolución experimentada por las fuentes personales y epistolares en la historiografía más reciente sobre las migraciones, y más concretamente en el País Vasco, al que me referiré especialmente en lo sucesivo, por gozar de un conocimiento más próximo sobre este espacio político-cultural. A este respecto, uno de los primeros aspectos que lo caracterizan, y que en cierto modo podría parecer sorprendente, es el momento relativamente temprano en el que las cartas y otros documentos personales comenzaron a ser utilizados en la investigación sobre las migraciones. De hecho, podemos remontarnos a los últimos años de la década de 1980 para encontrar las primeras menciones a cartas particulares en los entonces aún escasos estudios publicados.

Más aún, el modo en que tales documentos fueron recibidos por la historiografía fue igualmente sorprendente, teniendo en cuenta el contexto militante que, por aquellos años, rodeaba a este tipo de fuentes. En el caso de la emigración vasca, tales documentos aparecían insertos en investigaciones que podemos calificar más o menos de tradicionales, procedentes del incipiente mundo de la historiografía universitaria vasca, y fuertemente imbricadas en las tradiciones historiográficas precedentes. En tales estudios, sin embargo, los historiadores no ponían reparos a compaginar las fuentes más clásicas — documentos oficiales y

\footnotetext{
${ }^{6}$ Especialmente: Núñez Seixas $(2000,2001)$. Para el caso vasco, las más recientes reflexiones historiográ-
} ficas de Aramburu Zudaire (2005). 
administrativos, estadísticas, contratos protocolizados- con otras más novedosas como la prensa, ${ }^{7}$ la literatura popular ${ }^{8}$ y, por supuesto, las cartas. ${ }^{9}$

En cierto modo, la rapidez con la que se produjo la aceptación de las nuevas fuentes personales se explica no tanto porque el estudio de las migraciones se hallara sujeto a los cambios historiográficos que se estaban produciendo por aquellos años en España, sino porque este mismo campo de estudio era en sí mismo un producto más de dichos cambios. De hecho, entre 1980 y 1992 se conjugaron varios hechos que vinieron a modificar, para bien, el panorama de la investigación histórica en el País Vasco. El propio cambio de régimen político en España, desde la dictadura franquista hacia la democracia, con las nuevas posibilidades de libertad para la expresión y las ciencias humanas y sociales - especialmente en el campo de las interpretaciones historiográficas—, se hallaba sin duda en la base de dicha transformación; pero a ello también se le unieron otras cuestiones igualmente relevantes, como:

a) En el contexto particular del País Vasco, la creación en 1980 de la primera universidad pública, que permitió el surgimiento de una masa crítica de historiadores que en su gran mayoría dirigieron sus análisis a la reinterpretación del pasado de Euskadi. Puede afirmarse sin temor que aquel momento supuso el auténtico nacimiento de la profesión del historiador en el País Vasco. De este modo, junto con la incorporación de una generación nueva y más numerosa de historiadores, se ampliaron igualmente los campos de estudio hacia los que dirigían su mirada. Y si bien es cierto que, por razones fáciles de entender, cuestiones como la industrialización o el nacionalismo han sido los temas estrella en los estudios sobre la época contemporánea en las décadas posteriores (Azcona Pastor 1992: 10), no fue esto óbice para que también hubiera un desarrollo en otros

${ }^{7}$ Javier Díez Noci (2001) fue uno de los primeros en incursionar en el terreno de la prensa creada por los emigrantes vascos en América.

${ }^{8}$ El mejor estudio sobre la emigración ultramarina en la literatura popular vasca o bertsolarismo de los siglos XIX y XX está elaborado por un investigador del campo de la literatura (Urkizu 1995); sobre esta obra cfr. Álvarez Gila (1998). Uno de los primeros historiadores que se atrevió a usar esta fuente fue Azcona Pastor (1992): un texto del siglo XIX en el que un anónimo emigrante vasco describe en verso las vicisitudes por las que pasa desde su embarque hasta la llegada a Buenos Aires.

${ }^{9}$ En su momento, el metodológicamente débil trabajo de Pildaín Salazar (1984) incluía en el último capítulo una serie de cartas personales de emigrantes que se habían conservado en el mismo Archivo de Protocolos de Oñati, sobre el que había basado su estudio. 
campos, quizá aparentemente no tan atractivos pero no por ello menos fructíferos, tales como las migraciones.

b) Aquellos mismos años vieron nacer, además, uno de los primeros casos de lo que en cierta ocasión se ha venido a denominar la "historia conmemorativista" o "centenarista". Nos referimos a la práctica, que luego ha venido repitiendo la historiografía española en décadas posteriores, de dedicar grandes cantidades de recursos, de todo tipo y procedencia, a la investigación, estudio y divulgación histórica, ligadas a la conmemoración de las grandes gestas patrias. En el caso que nos ocupa, y teniendo en cuenta que uno de los destinos preferentes de las migraciones españolas contemporáneas, al menos hasta mediados del siglo XX, fue el continente americano, la fecha "mágica" de 1992 desató una auténtica competición entre gobiernos central y autonómicos, corporaciones locales y provinciales, entidades financieras, fundaciones y otros patrocinadores públicos y privados, por financiar con generosísimos aportes monetarios cualquier tipo de trabajo histórico que, enmarcado en el Quinto Centenario, resaltase las vinculaciones entre España y sus antiguas colonias ultramarinas.

Algún día tendremos que hacer una reflexión seria y profunda sobre los pros y los contras de este tipo de hacer historia a salto de calendario. En todo caso, es necesario reconocer que los estudios migratorios fueron uno de los grandes beneficiados del aporte monetario, rayano al despilfarro, que recibió la Historia durante el lustro largo que duraron los fastos del centenario. ${ }^{10}$ Los resultados, desde el punto de vista cuantitativo-productivo, fueron evidentes. En el caso del País Vasco, no menos obras sobre las migraciones ultramarinas, tanto libros de autoría individual como volúmenes colectivos, fueron editados entre 1989 y 2000; frente a las escasas cuatro obras que habían visto la luz en las nueve décadas precedentes del siglo. Dos fueron, además, las características reseñables de ese boom editorial que se experimentó alrededor de 1992:

a) En primer lugar - y esto es un rasgo que no sólo afectó a la producción historiográfica vasca-, el foco de atención de los estudios pasó del marco

\footnotetext{
${ }^{10}$ Quizá el ejemplo más elaborado de este comportamiento propio de nuevo rico fuera el Congreso de Historia del Descubrimiento organizado en diciembre de 1991 por la Real Academia de la Historia, bajo la presidencia de Antonio Rumeu de Armas (Tesoros 2001: 87). Las sesiones de este congreso tuvieron lugar en dos sedes, Sevilla y Madrid, previéndose el traslado de los congresistas, tanto ponentes como asistentes registrados, en avión entre una y otra ciudad a cuenta de la organización.
} 
nacional a otros marcos geográficamente más reducidos, tanto regionales como comarcales o incluso locales. Más que hablar de emigración española en singular, los historiadores comenzaron a fijarse en las profundas diferencias en lo tocante al comportamiento migratorio que presentaban las diferentes regiones. Cualquier visión general de la emigración española que partiera del uniformismo sería siempre errónea y parcial: explicar la emigración a América desde Euskadi o Cataluña aplicando los índices de pobreza de Andalucía o Extremadura sería tan absurdo como pintar a un londinense ataviado con el tradicional kilt escocés. El altísimo grado de variabilidad interregional en los diversos parámetros que atañen a las migraciones exigen, al menos, combinar la visión general con la mirada particular, si no queremos incurrir en errores rayanos al disparate. ${ }^{11}$ Cierto es que detrás de la nueva fragmentación del campo de estudio, de lo nacional a lo regional, no se hallaban tanto cuestiones epistemológicas como crematísticas: el reciente nacimiento del entramado institucional del Estado de las Autonomías consagrado por la constitución de 1978 dio nacimiento a una serie de poderes autonómicos que pusieron su empeño en promover los trabajos que enfocaran la cuestión desde la relevancia de destacar el "aporte" de tal o cual región a la presencia y acción española en América. Tales planteamientos podían haber dado lugar a una miríada de trabajos teñidos del más deleznable provincianismo paleto y, de hecho, así ocurrió en ocasiones. Pero es justo reconocer que una notable mayoría de los historiadores supieron hacer de la necesidad virtud y aprovechar la oportunidad para evitar que los estudios "regionalizados" de la emigración no fueran el punto de partida de una nueva serie de cantos y gestas patrios de regusto añejo pero en versión geográficamente reducida.

${ }^{11}$ Como señala Da Orden (2005: 31), "un tópico que recorre gran parte de la literatura sobre la emigración masiva de los españoles hacia América es el de la extrema pobreza que habría arrojado a miles de hombres y mujeres a dejar sus pueblos y buscar el sustento en otras tierras. Presupuesto que en buena medida retoma las voces de los contemporáneos críticos del sistema vigente y que también difundieron y popularizaron las canciones, poesías y narraciones de la época. [...] A poco que se profundiza en el tema los mismos testimonios suelen dar indicios de una posición no siempre coincidente con tal situación. Por lo demás la historiografía española de los últimos años da cuenta de una realidad muy diversa en cuanto a las caracteristicas del mundo rural del que partió la mayoría de los migrantes. Como la propia geografía, la sociedad y la economía españolas ofrecen una pluralidad de contextos difícilmente generalizables. De ahí, como se ha observado, que el estudio de las causas de la emigración presente serios problemas cuando se pasa de la escala nacional a niveles más acotados de análisis”. 
b) De este modo, regiones de fuerte tradición migratoria ultramarina, incluso hasta épocas muy recientes, comenzaron a contar con una incipiente historiografía centrada en los estudios migratorios. Mas dicha historiografía, a pesar de su juventud —o precisamente por este motivo—, fue desde el principio más receptiva a los cambios de paradigmas historiográficos que se estaban operando por aquellos años en el contexto europeo y también - aunque con cierto retraso- en España. Frente a la hasta entonces dominante visión de los estudios migratorios como una rama de la demografía histórica, centrada en el viejo debate de la cuantificación y de la causalidad, emergió lo que podríamos llamar una "historia social", o incluso una "historia cultural" de la emigración. Se incorporaron, por ejemplo, avances metodológicos como la teoría de la emigración en cadena y las redes migratorias, adoptada y adaptada por la historia de las migraciones desde la sociología ya en la década de 1960; y se abrieron nuevos enfoques o perspectivas de análisis, tales como los procesos de inserción y adaptación de los emigrantes en su nuevo entorno, la relación de los emigrantes con su tierra de origen, la institucionalización del llamado "asociacionismo étnico" -otro neologismo, tomado prestado en esta ocasión de los migration studies norteamericanos-, la percepción y opinión pública sobre las migraciones, e incluso elementos culturales como el folklore, las tradiciones y las artes ligadas a los fenómenos migratorios. Los historiadores habían llevado exitosamente a término su reivindicación de no verse constreñidos a ser meros recontadores de pasajeros.

Es precisamente en este contexto en el que los investigadores se atreven a escarbar, tímidamente al principio pero sin pudor posteriormente, en otro tipo de nuevas fuentes que les permitieran acceder al conocimiento de esos otros aspectos de la historia de las migraciones que ahora atraían su atención. El concepto de la "historia desde abajo", a pesar de los problemas epistemológicos y el peligro del reduccionismo ideológico que en su momento pudo acarrear, se reveló sin embargo como una poderosa herramienta para alcanzar algunos de los objetivos planteados en las nuevas líneas investigadoras. Uno de los más importantes signos del cambio de los tiempos fue la transformación radical de la base documental preferida por los estudios demográficos: frente a la anterior predominancia de las fuentes macro, cuantitativas o legislativas, se pasó a un predominio de las fuentes micro, cualitativas o personales. 
Existen, en todo caso, muy pocos ejemplos de estudios sobre emigración vasca que se centren exclusiva o fundamentalmente en las cartas. Más aún, los pocos que hay son relativamente antiguos, visto en la perspectiva, y se dedican más a la recopilación y edición de colecciones documentales. De hecho, los primeros ejemplos aislados de edición de cartas de emigrantes son bastante anteriores al periodo en el que hemos situado el inicio de su uso historiográfico; $y$, de hecho, las ediciones a las que nos referimos se realizaron en contextos científicos muy diferentes a la historia y al estudio de las migraciones.

Hemos de remontarnos para ello a las últimas décadas del siglo XIX, cuando la emigración ultramarina vasca no era un objeto de la historia sino una palpitante cuestión del presente. Nos referimos aquí al uso que hicieron algunos periódicos del género epistolar, como una más de las herramientas con las que elaboraban sus páginas de opinión. Así, por ejemplo, el polígrafo alavés José Colá y Goiti utilizó en varios de sus escritos periodísticos contra la emigración cartas supuestamente remitidas desde América por emigrantes a sus familias, denunciando los abusos de enganchadores y agentes de las compañías navieras en las que se realizaban a América. ${ }^{12}$ Algunas otras cabeceras también llegaron a usar otro incipiente género, el de las "cartas al Director", publicando algunas misivas enviadas por emigrantes desde lugares tan distantes como Buenos Aires o Los Ángeles. En el caso de la prensa vasca, en su conjunto, tenemos noticia de la edición de cartas "americanas", tanto en los debates en torno al "problema de la emigración” que involucró a la prensa vasca en las últimas décadas del siglo XIX (Álvarez Gila 1993), como en otros acontecimientos políticos que tuvieron un gran eco entre las colonias vasco-americanas, tal como las reacciones suscitadas en el País Vasco-francés ante la ley de 1903 que suprimía la educación en manos de la Iglesia e imponía el uso obligatorio del francés en la enseñanza del catecismo (Díaz Noci 2003), o las expectativas en torno al proceso autonómico vasco en la II República, durante 1931 y 1932 (Álvarez Gila y Tápiz Fernández 1996). Todos estos documentos, sin embargo, aunque formalmente se presentan como fuentes epistolares, nacieron con una finalidad de difusión pública que las aparta un poco de la consideración básica de las cartas privadas como fuentes propias del ámbito íntimo de la persona.

${ }^{12}$ Una recopilación de sus más importantes escritos en Colá y Goiti (1883). 
Más cercanas a este concepto eran, sin embargo, otras cartas de emigrantes vascos que vieron la luz, sobre todo desde la década de 1960. En este caso nos encontramos ante auténticos documentos personales, que fueron rescatados y editados por filólogos, que buscaban en ellos no su contenido, sino sus rasgos lingüísticos y el idioma en que se hallaban escritos. ${ }^{13}$ Un elemento común de todos ellos es que se trata de cartas escritas en euskera y que venían a reflejar la parquedad con la que los propios vascoparlantes usaban su lengua oral en contextos escritos. Las cartas enviadas desde América por emigrantes y recopiladas por José María Satrústegui en Valcarlos-Luzaide (Navarra), publicadas en Fontes Linguae Vasconum, abarcaban desde el Montevideo de la década de 1840 hasta los desiertos de Nevada en la década de 1970.

En 1992 Jesús María Usunáriz Garayoa abrió la vía de la edición científica y sistemática de cartas de emigrantes con su conocida obra Una visión de la América del XVIII: correspondencia de emigrantes guipuzcoanos y navarros (editada en 1993 en la colección Mapfre América). Este libro constituía básicamente un complemento documental a un estudio sobre la emigración navarra desarrollado por el mismo autor, que se había basado en gran medida en un vaciado de fuentes epistolares obtenidas del Archivo Diocesano de Navarra. ${ }^{14}$ En las dos décadas posteriores, han sido varios los autores que han seguido la misma senda, dando a la luz nuevas colecciones epistolares. En este punto, son especialmente destacables los esfuerzos realizados por el equipo de investigación de la Université de Pau et des Pays de l'Adour, nucleado en torno al catedrático Adrián Blázquez, que han realizado una exhaustiva labor recopiladora de fuentes personales referidas a la emigración ultramarina desde las regiones del Béarn y del País Vasco-francés, en el departamento de los Pirineos Atlánticos (Blázquez, Bruneton-Governatori y Papy 2002). Respecto a los trabajos historiográficos elaborados principal o únicamente usando fondos epistolares, éstos son todavía muy poco numerosos, aunque interesantes, destacando las obras de Martina (2004), Larrazabal Saitua (2007) o Ugarte (2010), entre otros. Esto no ha

${ }^{13}$ El autor más prolífico en esta materia fue el académico José María Satrústegui, miembro correspondiente de la Academia de la Lengua Vasca en Navarra. Siendo párroco de la localidad fronteriza de Valcarlos-Luzaide, se dedicó a recopilar numerosos testimonios personales del uso de la lengua vasca en la localidad, entre ellos "un buen número de cartas" (Iñigo Ariztegi 2004: 375).

${ }^{14}$ Pocos años antes, Satrústegui (1979a, 1979b) había realizado algunas interesantes catas en este mismo Archivo Arzobispal de Pamplona, sección de "Procesos". 
sido óbice, sin embargo, para que se haya podido constatar un creciente uso de las fuentes epistolares y otras fuentes privadas, tales como las fuentes orales, las memorias o las fuentes iconográficas (Manfredi 2009), en estudios más o menos amplios sobre la emigración vasca a América. En resumen, una valoración apresurada sobre este proceso nos llevaría a deducir que la aceptación de las fuentes epistolares en el campo de los estudios migratorios ha sido, en el caso del País Vasco, razonablemente exitosa.

\section{EXPECTATIVAS}

No puede decirse lo mismo, en cambio, sobre las expectativas que se generaron, en un momento inicial, en torno a las posibilidades que las fuentes personales, y en concreto las epistolares, podían ofrecer a los estudios migratorios. En el caso de las cartas, se entendía que habiendo sido éstas, durante largo tiempo y hasta el advenimiento y uso masivo del teléfono e internet en las últimas décadas, el único medio de comunicación asumible entre los distintos miembros de las familias asentados a uno y otro lado del océano, sus informaciones habrían de ser de una riqueza tal que su aporte sería a la postre de capital importancia en la renovación de las interpretaciones historiográficas sobre el fenómeno migratorio.

¿Qué aspectos podrían verse, según se pensaba, más beneficiados por la incidencia de estas fuentes, antes de que los historiadores se pusieran manos a la obra en su caza y captura? Sobre este punto, existían - y en cierto modo aún existen, aunque implícitamente- ciertos elementos de coincidencia.

En primer lugar, se hallaba la idea ampliamente compartida de que el uso de las fuentes epistolares iba a constituirse en la llave para aprehender la percepción del acontecimiento desde la perspectiva de los protagonistas del fenómeno migratorio. Como, por ejemplo, señalaba María Liliana Da Orden en 1997:

[...] tanto las imágenes — con su especificidad—, como la producción escrita —muchas veces también incluida en el dorso de las fotografías - constituyen en la mayoría de los casos el único testimonio de las "voces" de los protagonistas de la gran emigración hacia América de fines del siglo XIX y comienzos del XX, así como de la oleada de posguerra. 
Junto con los diarios, las cartas y fotografias constituyen una fuente inestimable de las vidas de la "gente común", vistas desde su propia perspectiva. En tanto producto de sujetos singulares, manifiestan experiencias y percepciones únicas. ${ }^{15}$

Efectivamente, como bien afirma Da Orden, las fuentes preferentemente utilizadas hasta ese momento para el estudio de la emigración eran siempre externas, es decir, no producidas por los protagonistas del fenómeno, sino por agentes y observadores ajenos a los propios emigrantes. Estadísticas, documentos oficiales, artículos periodísticos, sermones y pastorales episcopales coincidían en un rasgo: en todos ellos se habla de los emigrantes, pero no hablan los emigrantes. En este sentido, la fuente personal parecía constituir el contrapunto necesario para complementar aquellos aspectos del conocimiento histórico de las migraciones que esas fuentes externas no nos podrían proporcionar en modo alguno. De hecho, esta idea subyace de forma más o menos explícita en la obra de investigadores que han usado las fuentes epistolares como elementos indispensables, "tesoros documentales" imprescindibles para una completa cabal comprensión de los fenómenos migratorios, cuya recuperación urgía a los historiadores:

Las escrituras cotidianas de los emigrantes son ese terreno donde pueden conjugarse ambas perspectivas. Su dimensión de documentos íntimos y al tiempo colectivos, junto a las distintas características que se han venido subrayando líneas atrás, es lo que ha llevado a considerar las escrituras personales como fuentes indispensables para conocer la vida privada de los emigrantes, como documentos vivos y de primera mano que ponen de manifiesto la vertiente humana de la emigración. La exhumación de dichos escritos pone en manos del historiador, y a disposición del público, todo un tesoro documental que sigue, en gran medida, sin ser descubierto en archivos públicos, oculto entre expedientes y documentos administrativos; en colecciones privadas, muchas de ellas conservadas todavía en el seno familiar y otras donadas a los archivos donde se está salvaguardando la escritura y la memoria popular, y la gran mayoría olvidadas en el fondo de esos baúles de emigrantes similares al que ha dado comienzo a esta historia (Sierra Blas 2004).

15 "A recuperación da experiencia da emigración galega na Arxentina: as cartas familiares e as fotos dos emigrantes", conferencia de María Liliana Da Orden, Curso de Verán "As migracións nas sociedades contemporáneas: os desafíos na Galicia actual”, Caldas de Reis, julio de 2007. 
Un segundo punto de coincidencia venía establecido a la hora de calibrar aquellos elementos de los procesos migratorios cuyo conocimiento sería notablemente mejorado mediante el uso de las fuentes personales. Así, en primer lugar, se consideraba que dichas fuentes permitirían una revisitación crítica, una nueva vuelta de tuerca al antiguo - y hasta cierto punto agotado — debate sobre las causas y mecanismos de la emigración, añadiendo nuevas luces a los aportes hechos desde fines de la década de 1950 con los estudios pull-push, siguiendo las recomendaciones hechas por Thistlethwaite (1960) en el Congreso de Ciencias Históricas celebrado en Estocolmo en 1960. El abordaje tradicional del problema de las causas de la emigración había adolecido de un notable carácter mecanicista y reactivo, que hacía del emigrante poco menos que un autómata, un ser que se movía empujado por causas que escapaban a su comprensión, control y conocimiento: la evolución de la economía, la globalización de los mercados, incluido el del trabajo, las grandes transformaciones sociales y productivas...

Frente a esta visión, las fuentes personales contribuirían a reivindicar al emigrante como un ser racional y activo en el proceso de toma de decisión ante los desafíos que supone cualquier proceso migratorio (individual o colectivo). De hecho, algunas de estas fuentes nos presentan la emigración no tanto como una respuesta obligada ante los avatares de la economía, sino como una práctica social fuertemente arraigada e imbricada en el entramado socioeconómico de las sociedades que lo practican; así, por ejemplo, los testamentos de fines del siglo XVIII y comienzos del siglo XIX de Carranza, en el occidente vizcaíno, mostraban que la emigración era algo previamente asumido en el seno de muchas familias como la salida naturalmente esperable de varios de sus miembros más jóvenes, señalándose para ello diversos cauces de solidaridad intrafamiliar para su financiación, de un modo independiente a la evolución de la variables económicas (Álvarez Gila 2002).

El uso creciente de fuentes personales y epistolares se relacionaba así, muy estrechamente, con el éxito que tuvo en la historiografía española el uso de la teoría de las cadenas migratorias en los estudios que comenzaron a producirse por aquellos años. Dentro de este esquema, la correspondencia adquiría así una doble importancia, no sólo como fuente para su conocimiento, sino como mecanismo esencial y clave en la configuración y mantenimiento de dichas cadenas. Las cartas deberían ser así el hilo conductor a través del cual se produ- 
cía la transferencia de informaciones que permitía la pervivencia, reformulación y reactivación de los mecanismos que daban origen a la migración en cadena, sobre todo en cuatro aspectos esenciales:

1. Como mecanismo para compartir la información sobre las oportunidades de trabajo, asentamiento y progreso que se abrían ante los nuevos emigrantes. Como señala Gibelli (1997: 296-97):

La información depositada en las cartas acerca de las características y condiciones de los diferentes países receptores del flujo migratorio era tenida muy en cuenta por todos; mientras que se dudaba de otros medios de comunicación que, a modo de instrumentos propagandísticos, trataban de atraer a los emigrantes hacia determinados destinos y actividades. Las cartas, como fuentes de información, como herramientas de transcripción de la realidad, influyeron de manera decisiva en la formación de opinión y en la toma de decisiones acerca del destino a elegir, así como en la creación y regulación mismas de las cadenas migratorias.

2. Como sistema de llamada, ya que las cartas y otras comunicaciones similares escritas han mantenido hasta fechas muy recientes su importancia como elemento probatorio y justificativo de la emigración. Su valor era doble, tanto ante las autoridades del país de partida como del país de acogida. Ante las primeras, estas cartas permitían solventar los trámites para la obtención del preceptivo pasaporte y otros permisos de partida; ante las segundas, otorgaba la seguridad necesaria para admitir la presencia legal del inmigrante, quien por este motivo mostraba que no era un elemento potencialmente peligroso en cuanto a hallarse sin protección en un entorno extraño y hostil, sino un aporte productivo al desarrollo del país.

3. Como fortalecedor de los lazos afectivos entre los extremos de la cadena migratoria y las fracciones de la familia separadas por la distancia. Por ejemplo, la comunicación de los ritos de pasaje, por lo general y cuando era posible acompañado de testimonios visuales como las fotografías, permitía una participación simbólica de todos los miembros en dichos ritos, y contribuía a mantener la unidad del calendario ritual y afectivo de todos sus miembros. Las cartas, de hecho, están plagadas de noticias e informaciones que el historiador está tentado de calificar muchas veces de intrascendentes, pero que adquirían una importancia notable como elementos estructuradores de los lazos afectivos: cambios de residencia, mejoras o redecoraciones de las casas, informes de las últimas novedades 
en la vida social de la comunidad de origen, expresión de recuerdos y saludos por parte de viejos amigos o conocidos, etc.

4.- Como espacio de negociación de las relaciones de derechos y deberes mutuos entre ambos extremos de la red migratoria, destacando principalmente los vinculados a la economía doméstica (gestión del patrimonio familiar, remesas, etc.).

A esto se añadía, finalmente, y ligado a los nuevos ámbitos de interés que estaban surgiendo en la historiografía, el deseo de recuperar la visibilidad en el discurso histórico de sectores sociales tradicionalmente escondidos o no adecuadamente valorados mediante el uso de las fuentes tradicionales, como por ejemplo la aplicación de la llamada "perspectiva de género", que permitió enfocar la cuestión de la participación femenina en los procesos migratorios desde unos presupuestos radicalmente diferentes a la idea dominante anteriormente, que veía en las mujeres meras seguidoras - como hijas o esposas - de decisiones que quedaban en manos masculinas. Muchas de estas expectativas no eran privativas de la historia de las migraciones, sino que se alimentaba de una suerte de "optimismo historiográfico" producido por la fascinación de la nueva fuente y el discurso ideológico elaborado en su entorno. No en vano muchos de quienes nos acercamos por entonces a estas fuentes nos comportábamos, haciendo bueno el saber popular, como niños con zapatos nuevos.

\section{LIMITACIONES}

Como ya hemos señalado, el tiempo ha venido a limar los excesos — de un ladoe irracionales reticencias - del otro lado - ante el uso de las fuentes personales, normalizándose su uso como fuente para la historia. Este proceso de normalización se ha dado de un modo simultáneo en dos ámbitos. En primer lugar, las fuentes personales han dejado de ser patrimonio de un sector específico y minoritario de la historia, para entrar en la historiografía común o mainstream. En segundo lugar, se ha producido una progresiva sujeción de las fuentes personales a la crítica formal propia del trabajo historiográfico, abandonando la hasta cierto punto sacralización con la que se las llegó a presentar en un momento.

De este modo, las fuentes personales nos han mostrado, como cualquier otro tipo de fuentes, no sólo sus posibilidades, sino también sus límites. A pesar de 
lo que pensaban, o pensábamos, muchos hace no tantos años, este tipo de fuentes no es la panacea que va a venir a modificar todo nuestro conocimiento, aunque sí presente aportes innegables y abra perspectivas no usuales antes. ¿Cuáles serían estas limitaciones? A mi entender, las principales podrían resumirse en: a) su carácter fragmentario; b) su carácter elitista; y c) las dificultades para aprehender su contenido.

\section{Su carácter fragmentario}

Una fuente histórica ideal es aquella que nos llega en su totalidad, del modo más completo posible, con elementos que nos permiten conocer todo el proceso de su creación y el contexto en el que se producen los acontecimientos a los que hace referencia directa o indirecta. Aunque la fuente histórica perfecta no pasa de ser una utopía, los historiadores nos conformamos con aplicar este apelativo a aquellos conjuntos documentales que nos permiten, al menos, un conocimiento cabal y razonablemente amplio de un fragmento más o menos homogéneo del pasado, sin que las vicisitudes del tiempo hayan provocado excesivas lagunas.

Es precisamente este concepto, "conjunto documental", la clave de todo el asunto. En el caso del uso de la correspondencia como fuente histórica, no se trataría tanto de contar con cartas como piezas aisladas, sino de disponer de epistolarios completos. La correspondencia es siempre un proceso entre partes, dos como mínimo, aunque no son pocas las ocasiones en los que son más los participantes, en un diálogo escrito y dilatado en el tiempo. Cada carta constituye en sí solamente un fragmento de ese diálogo, que es preciso conocer en su conjunto para entender cabalmente el contenido, tanto directo como contextual, de cada una de sus piezas. En una correspondencia hay una transmisión constante de información, que varía con el tiempo, en un sistema con muchos elementos autorreferenciales (menciones a situaciones, noticias o comentarios ya antes mencionados, sistemas de pregunta/respuesta diferidas en el tiempo en diversas cartas, sobreentendidos y elipsis de aquellas cuestiones ya asumidas en cartas precedentes, etc.). El contenido de una carta concreta sólo puede ser entendido correctamente inserto en su contexto, al menos en el contexto de la correspondencia a la que pertenece, igual que cualquier documento de archivo 
no puede ser entendido por sí solo, sino en el expediente o conjunto documental en el que se inserta.

Lamentablemente, la mayoría de las cartas que se conservaban en archivos públicos, sobre todo aquellas que eran producto de las "gentes del común", no suelen cumplir ninguna de estas condiciones. Tradicionalmente, los únicos epistolarios organizados que se conservaban en los archivos tradicionales correspondían, según la época, a las correspondencias de grandes casas nobiliarias, monasterios, empresas y otras instituciones políticas, económicas o eclesiásticas: es decir, de aquellos mismos protagonistas de la "historia elitizada" tan denostada por los valedores iniciales del uso de estas fuentes. Cierto es que en los últimos años se han hecho esfuerzos y avances en la recuperación de archivos epistolares de otras procedencias sociales, pero así y todo, incluso hoy en día la balanza se sigue inclinando claramente del lado de los poderosos.

De hecho, la mayoría de las cartas populares que se conservaban - y se conservan- en archivos públicos son, a lo sumo, ejemplares sueltos y, en todo caso, siempre muestras limitadas de una correspondencia mucho más amplia. Esta situación, además, afectaba por igual, tanto a quienes centran sus estudios en la emigración ultramarina de época moderna, como de la contemporánea.

Un efecto de esta situación es el carácter sesgado del contenido de las cartas, ya que su inclusión en los archivos en los que han acabado por conservarse, a diferencia del resto de cartas que en su momento habrían formado parte de la misma relación epistolar, obedecía a una serie de motivaciones que nunca son coincidentes con aquellas otras razones que llevan a los historiadores de hoy en día a poner su atención en la correspondencia como fuente.

En el caso de la emigración vasca a América, por ejemplo, los principales conjuntos documentales en los que es posible encontrar un número significativo de cartas relacionadas con la emigración proceden de:

1. Archivos diocesanos: fundamentalmente insertas en expedientes relativos a reclamaciones de bigamia, promesas incumplidas de matrimonio y otros asuntos de moralidad y costumbres que caían dentro de la jurisdicción de los tribunales eclesiales. Ésta es, por ejemplo, la base de la colección editada por Usunáriz Garayoa a la que nos hemos referido antes. ${ }^{16}$

\footnotetext{
${ }^{16}$ Algo similar, usando archivos americanos, en Sánchez Rubio y Testón Núñez (1999).
} 
2. Adjuntos a solicitudes de licencias de embarque, permisos de emigración y obtención de pasaportes, según las épocas. En todos estos casos, solía ser preceptivo que el solicitante de cualquiera de estos documentos que lo habilitaban para poder marchar al Nuevo Mundo a iniciar su aventura migratoria mostrara alguna prueba documental de las razones que aducía para ello. La presencia de un pariente o amigo que allí lo reclamaba solía ser la más fácilmente justificable; y, para ello, la presentación de una carta — original o copia protocolizadaera el medio más habitual. Son muy conocidas, por haber sido ya publicadas en gran número, ${ }^{17}$ las cartas conservadas en las licencias de embarque del Archivo General de Indias para los siglos XVI al XIX (según las épocas, se pueden localizar en las secciones de Arribadas, de las diferentes audiencias receptoras), así como en el Archivo General de Simancas y, ya en el siglo XIX para Cuba, Puerto Rico y Filipinas, en la sección de Ultramar del Archivo Histórico Nacional.

También suelen ser muy ricos en este tipo de documentación los archivos municipales, dado que en muchos pueblos solía ser el alcalde, en sus funciones de juez administrativo, el encargado de aceptar los testimonios y otorgar las licencias, sobre todo en el caso de menores que eran enviados por sus familias a destinos en América. En este caso, sin embargo, no hay una uniformidad en el comportamiento ni en el volumen de cartas conservadas, dependiendo de factores tales como la existencia o no de una fuerte tradición migratoria, así como las vicisitudes que hayan podido afectar a la conservación de las fuentes municipales.

3. Adjuntos a documentación militar. Tras la instauración progresiva en las provincias forales del servicio militar obligatorio - en 1841 en Navarra, y en 1877 en Álava, Guipúzcoa y Vizcaya—, los expedientes de quintas han venido a conservar ejemplos de cartas, presentadas por los familiares de reclutas llamados a filas pero residentes en el extranjero, bien para justificar su paradero, bien para certificar el cumplimiento por parte de tales emigrantes de sus obligaciones militares, ya fuera presentándose para la talla ante el cónsul español correspondiente, ya fuera consignando las cantidades legalmente establecidas para obtener la exención —entre 6000 reales y 2000 pesetas, según las épocas—. Este bloque documental es el menos abundante y más fragmentario de los tres.

${ }^{17}$ Vid. Otte (1988), Macías Domínguez y Morales Padrón (1991), Zaballa Beascoechea (1999), Martínez Martínez (2007) y Martínez de Salinas (2007). 
Por lo general, las cartas conservadas insertas en estos bloques documentales previamente descritos suelen servir más para informar acerca de elementos externos, que acerca de la propia relación epistolar.

4. Existe, además, un número cada vez más abundante de epistolarios personales y familiares que se han ido incorporando al dominio de la historia, generalmente de épocas contemporáneas, gracias a la labor de recopilación de historiadores y archiveros concienciados. Pero incluso en este caso, no tenemos la constancia de que las cartas que se han conservado reflejen epistolarios completos; más aún, ni siquiera podemos estar seguros de que los criterios para su conservación hayan ido más allá de la pura casualidad, de factores puramente afectivos, o de otros tan aleatorios que el historiador puede considerar sorprendentes (cartas que fueron conservadas porque los sellos "eran bonitos").

\section{Su carácter elitista}

Puede parecer aparentemente paradójico que consideremos elitista a un tipo de fuentes que fueron reivindicadas, no hace mucho tiempo, como el remedio para presentar la voz del pueblo, en contraposición a la saturación de conocimiento y fuentes sobre las élites económicas, políticas y sociales. Por supuesto, estamos entendiendo este término en su sentido más lato, con la intención de incidir en la disímil realidad social de la escritura, en unas sociedades en las que no todo el mundo tenía la misma capacidad de acceso a las habilidades lectoras y escritoras. De este modo, la relación entre el sujeto (el emigrante y aquellos con quienes mantiene una correspondencia) y el objeto (la carta) no es en modo alguno neutral, sino que se halla fuertemente matizada y discriminada por factores de índole sociocultural.

El primero de estos factores es, sin duda, el nivel de alfabetización, tanto de la sociedad en general como, sobre todo, de los emigrantes. Efectivamente, éste es un dato fundamental que condiciona desde la misma existencia y abundancia de fuentes personales escritas, hasta el modo en que deben ser contextualizadas e interpretadas metodológicamente. La alfabetización generalizada o cuasi-universal es un hecho históricamente muy reciente; y así, en el periodo de las grandes migraciones ultramarinas todavía eran muy grandes las bolsas de analfabetismo en las sociedades europeas de las que partieron el grueso de los 
emigrantes. Si bien es cierto que diversos estudios han puesto de relieve que, por lo general, los emigrantes suelen presentar unos niveles educativos y lectoescritores superiores a los de la sociedad de la que proceden, esto no debe hacernos olvidar que las migraciones se dieron en un tiempo y un espacio en los que el analfabetismo era la norma y no la excepción.

El resultado es que, para muchos migrantes, el acceso a la carta - tanto en calidad de lectores como, sobre todo, de productores - era un camino plagado de muchas dificultades. Esto era así incluso para aquellos que declaraban conocer las técnicas básicas de lectura y escritura, ya que es preciso señalar la diferencia entre conocimiento y destreza: el mero aprendizaje de una técnica, en este caso la escritura, no significa en modo alguno familiaridad, y mucho menos maestría. Como señala Sierra Blas (2004):

En su inmensa mayoría, los emigrantes estaban poco familiarizados con la escritura. Hasta el momento de su partida no habían tenido ni oportunidad ni necesidad de escribir. Las cartas y otros escritos de índole personal nos revelan esa escasa competencia gráfica, el bajo nivel de instrucción y las dificultades que el emigrante tenía para escribir: repeticiones temáticas y formularias; necesidad de recurrir a frases hechas, expresiones coloquiales o tópicos; uso continuado de interjecciones que reclaman la presencia física del destinatario; registros expresivos propios de la oralidad; errores gramaticales y ortográficos; incapacidad, en muchos casos, de organizar el discurso; una escritura deficiente, incierta e irregular; y, de manera muy habitual, la presencia de otras manos que escribiesen por ellos, bien fuesen amigos o conocidos (los denominados "escribientes vicarios") o escribanos públicos. Características todas ellas de una escritura inexperta, reflejo de los primeros contactos con el mundo de lo escrito derivados de las necesidades que imponían las circunstancias.

Un buen ejemplo de todo lo afirmado por Sierra Blas se puede ver en la siguiente carta, remitida desde Chile por un matrimonio de emigrantes vizcaínos en la primera mitad del siglo Xx. En este texto, a los errores ortográficos se le añade la absoluta carencia de signos de puntuación y la anárquica división entre palabras, hechos que reflejan el extremo carácter oral de la lengua manejada por los autores del texto, y sus evidentes limitaciones en el uso y aprovechamiento de las posibilidades del registro escrito: 
Algorta 22 de Enero 1906

Querido hijo

Emos recibido la tuya con fecha 21 de Diciembre y enterados de ella vemos que estais buenos de lo que nos alegramos mucho nosotros muy achacosos por el invierno tan duro que nos esta echando

Nos dices que teas casao y que tienes tres hijos y emos visto en fotografía tanto la madre como los hijos son guapos como para enseñar a cualquiera lo que deseo es que os lleves bien los genios los unos con otros y que seas buen marido para ella y buen padre para los hijos por que los que no se unen bien por mas que tengan dinero no tienen felicidad la buena union de casa bale mas que las riquezas así procura tener esa felicidad y que sea por muchos años

Sin mas por ahora recibe los recuerdos de todos los de casa y los nuestros como gustes que somos inolbidables padres

Juan Jose Saitua

Josefa Ibarra

Muchos besos a los niños de parte de los abuelos sarras ${ }^{18}$

Una consecuencia de lo anterior es que el historiador ha de acercarse a estos documentos con un cierto espíritu de escéptica prevención ante el posible alcance del contenido, debido sobre todo al grado de libertad que haya podido tener el escribiente o firmante de la carta para poder expresar completa, correcta y adecuadamente todo aquello que estaba en su ánimo comunicar. Si autor intelectual y autor material del texto coincidían, hemos de considerar hasta qué punto la ineptitud del escribiente en el manejo de la escritura y en el uso de registros idiomáticos ricos limitaba su capacidad de expresión; si ambos eran personas diferentes, como ocurría en otras ocasiones, a buen seguro existiría un elemento de censura previa de los contenidos expresados en la carta, debido a que quedarían expuestos al conocimiento de terceras personas (esto, por no hablar de la otra censura, la oficial, externa, pero que también influyó sin duda a la hora de limitar los contenidos que los autores de las cartas querían y podían expresar).

Un elemento añadido de este elitismo viene dado por el volumen de documentación personal escrita que nos han dejado los actores históricos, según su

\footnotetext{
${ }^{18}$ Reproducida en Larrazabal (2007).
} 
procedencia social y nivel cultural, que nuevamente vuelven a ejercer de una manera intensa su papel discriminatorio. Efectivamente, se aprecia en este punto que, a mayor nivel social y cultural, mayores y mejores son los bloques documentales que producen y se conservan. ${ }^{19}$

A esto se añade un segundo factor, no menos importante aunque, en el caso que nos ocupa, sistemáticamente obviado y minusvalorado por razones que escapan al territorio de lo científico: la cuestión del idioma.

Sobre este punto la historiografía española o, mejor dicho, aquellos estudios que se han hecho dentro y fuera de España sobre la emigración española "en general" (sin matizaciones regionales) acostumbraron a pecar, hasta fechas extraordinariamente recientes, de un fallo que ha condicionado muchas de las interpretaciones y conclusiones que se han ofrecido sobre los procesos migratorios hispanos a América. Todavía no hace mucho, era relativamente frecuente leer afirmaciones tales como que, a diferencia de otros grupos inmigrantes europeos en Latinoamérica, los españoles se encontraron con la ventaja relativa de no tener que realizar ningún tipo de adaptación idiomática y cultural. Era irrelevante si el inmigrante en cuestión procedía de Burgos, Ourense, Guipúzcoa o Gerona: todos ellos eran igualmente españoles y por lo tanto su idioma, como el valor en el servicio militar, se suponía que era el mismo de su sociedad de acogida.

Sin caer en el error fundamentalista de negar la mayor, y sin pretender equiparar totalmente la situación de los inmigrantes gallegos, vascos o catalanes con, pongamos el caso, italianos, rumanos o polacos judíos, lo cierto es que España no ha sido nunca un territorio homogéneo en lo lingüístico. La supuesta unidad idiomática de la que parten como un axioma estas interpretaciones es simplemente una falacia histórica o, de existir, es un hecho muy reciente. En el caso del País Vasco, por ejemplo, existen estudios ya clásicos que reflejan cómo el bilingüismo como hecho social generalizado no se dio en las comarcas vascoparlantes, por lo menos, hasta las generaciones posteriores a la Guerra Civil española (Cid Abasolo 2002). Antes de esa fecha, los vascoparlantes de nacimiento podían aprender el castellano de muy diversos modos, siendo la alfabe-

${ }^{19}$ Por ejemplo, Arroyo (2006). También es interesante el uso de la documentación epistolar familiar de los Manso de Velasco, familia riojana afincada en Bilbao a comienzos del siglo XIX, en Angulo Morales (2007). 
tización institucionalizada el más importante de ellos: un proceso que se fue generalizando según se fue extendiendo la implantación de la educación básica, que sólo se hacía en la lengua oficial del estado, sin que esto modificara la realidad social fundamentalmente monolingüe fuera del estrecho marco de los espacios oficiales y escritos (la escuela, la administración, el notario). Algunos autores, como Iriani (2000), han aducido este hecho (que prácticamente todos los emigrantes vascos que llegaron a Argentina conocían el castellano) para negar ipso facto que los vascos precisaran de ningún proceso de adaptación lingüística. No obstante, a pesar de que los emigrantes que partían de estas zonas contaran con conocimientos básicos de castellano, hemos de recordar nuevamente que aprendizaje no supone dominio, ni mucho menos la vinculación afectiva que se tiene con la lengua materna (Núñez Seixas 2002: 209-11). Para ellos el castellano sería siempre una segunda lengua, adquirida y, hasta cierto punto, ajena. ${ }^{20} \mathrm{Si}$ al débil y lento proceso de alfabetización le añadimos el hecho de que éste se realiza en una lengua diferente a la materna y de uso habitual en la sociedad de partida, hemos de coincidir en que se conjugan todos los factores para suponer que los emigrantes españoles de las clases populares que partían a América desde regiones que mantenían su propia lengua no gozarían, precisamente, de un bilingüismo perfecto; antes al contrario.

Los ejemplos que hemos manejado de correspondencia enviada por emigrantes vascos nos presentan un cuadro característico notable. En primer lugar, y aparentemente en contradicción con lo que acabamos de afirmar, la práctica totalidad de los escritos que se han conservado están en castellano, ${ }^{21}$ incluso en aquellos casos en los que la documentación adicional nos ha confirmado que tanto emisores como receptores de las cartas se comunicaban de forma oral exclusivamente en euskera. Esta práctica no era sino un reflejo de la situación diglósica de la sociedad vasca, en la que estaba profundamente interiorizada la división entre lengua oral (en muchos lugares el euskera) y lengua escrita (el castellano o, en las regiones norpirenaicas, el francés).

\footnotetext{
${ }^{20}$ Sobre este particular, cfr. las precisiones que hicimos en Álvarez Gila (1995).

${ }^{21}$ Esta afirmación, lógicamente, se circunscribe a los emigrantes vasco-españoles. En el caso de los vascofranceses, hay un índice apreciablamente superior de testimonios epistolares redactados en euskera. Estas diferencias responden a la existencia de una tradición lecto-escritora en euskera en el País Vasco-francés más desarrollada a lo largo del siglo XIX. No en vano, por ejemplo, las dos primeras iniciativas periodísticas en lengua vasca fueron implementadas en Bayona y en California (de la mano de un emigrante de origen vasco-francés).
} 
En segundo lugar, tras el texto aparentemente en castellano suelen emerger rastros inequívocos de la presencia de la lengua original, en nuestro caso la vasca, a veces mediante el uso de expresiones e interjecciones, de saludos y rituales (Angulo Morales 1995), o de palabras sueltas, ${ }^{22}$ pero más habitualmente mediante artefactos metalingüísticos en los que se combina el uso de estructuras sintácticas vascas con palabras castellanas. Nos referimos con esto, particularmente, a las peculiaridades del uso de la lengua castellana en boca de vascoparlantes nativos, cuya presencia en la tradición literaria española arranca ya desde los autores del Siglo de Oro, que dejaron testimonios de lo que entre jocosa y despiadadamente denominaban "concordancia vizcaína”. Dejando a un lado el hecho de que los textos más conocidos de literatos españoles en supuesta concordancia vizcaína no dejan de ser, en su mayoría, fantasías burlescas sin una base real filológica, lo cierto es que existe un conjunto de rasgos característicos producto de las interferencias entre ambos idiomas.

Tomemos como ejemplo la siguiente carta, que a pesar de corresponder a un periodo bastante temprano, comienzos del siglo XIX, nos permite ofrecer una serie de reflexiones sobre el particular:

A d ${ }^{\mathrm{n}}$ Meliton de Bulucua en casa de Mendiola - Guernica

Muy $S^{\text {or }}$ mio y Amigo: He recibido una esquela por manos de su sobrino Juan Pepe, quedandome enterado sobre lo que en ellos dice. Aier en la Romeria de Mujica ablemos Arostegui y los dos que tenía que haber unos rr en el tabernero de Porttal, y anttes de $S^{n}$ Pedro $q^{e}$ pensaba cumplir con su obligacion, $q^{\text {e }}$ mañana me he estado pa abisar a Vmd. estto mismo y con tantto mande Vmd. su Serv ${ }^{\mathrm{r}}$ Q.S.M.B.

Belaustegui

Oy 4 de Junio $1816^{23}$

El contexto en el que se escribe esta carta es sumamente significativo. Francisco de Beláustegui, su autor, es un antiguo emigrante vizcaíno, cercano ya a la sesentena, que tras haber pasado más de cuarenta años fuera del País Vasco, en Cádiz y Buenos Aires, ha regresado a su pueblo natal a ejercer de indiano enriquecido. Se trata

22 En el ejemplo anterior, el uso del apelativo sarra (zaharra: viejo), usando en un contexto familiar.

23 Archivo de la Real Chancillería. Valladolid. Sala Vizcaya. 1818. Sobre la figura de Francisco de Beláustegui, vid. Siegrist de Gentile (2004). 
además de una persona que ha pasado su vida en el comercio interatlántico al por mayor, por lo que se supone que ha sido una persona de conocimientos y amplia base de relación social allí donde estuvo residiendo. ${ }^{24}$ Sin embargo, el texto que escribe - de su puño y letra - nos presenta la fortaleza con la que los elementos sintácticos de su lengua materna, a la que abandonó junto con la infancia, siguen persistiendo en sus estructuras mentales. Algunas frases son, literalmente, traducciones palabra a palabra que adquieren su sentido si se piensan en euskera y no en castellano. Así, por ejemplo, cuando señala que hablaron "Aróstegui y los dos", no hace sino repetir la estructura propia del euskera para incluir al hablante en una relación de personas, que no usa el pronombre personal "yo" sino el número de personas incluidas en dicha relación. ${ }^{25}$ Lo mismo puede decirse, por poner otro ejemplo, de la estructura "me he estado para avisar a Vmd.", hasta cierto punto comprensible aunque no muy correcta en castellano, dado que es la traducción literal de la estructura propia del euskera "Zuri abisatzeko egon natzaizu" ("me obligo a avisarle a usted").

Si este tipo de interferencias se dan en la correspondencia de personas de un nivel social elevado, es lógico deducir que aquellos de otras procedencias sociales más populares sufrirán similares, cuando no mayores, dificultades de expresión, con lo que su correspondencia sufrirá las cortapisas de un doble filtro (paso de lengua oral a lengua escrita y traducción del euskara al castellano). Existen, en este punto, abundantes testimonios sobre la falta de capacitación y las dificultades de expresión en lengua castellana de emigrantes vascoparlantes en la segunda mitad del siglo XIX y primeras décadas del XX, si bien aún no contamos con un estudio sistemático que intente calibrar la controvertida cuestión de la lengua y la emigración en el caso de los vascos (Álvarez Gila 2006).

\footnotetext{
${ }^{24}$ Además de ser uno de los más acaudalados comerciantes de Buenos Aires en las últimas décadas de dominio colonial, fue miembro del Real Consulado, secretario de la Hermandad de Caridad, presidente del convento del Hospital de Mujeres y síndico del monasterio de las Capuchinas. Durante las invasiones inglesas de Buenos Aires tuvo una participación destacada en la defensa de la ciudad. Participó en el Cabildo abierto de 1810, manteniendo una postura contraria a la independencia.

${ }^{25}$ Así, no se dice "tú y yo", sino (literalmente) (*)"tú y los dos" ("zu eta biok"), como aparece en este ejemplo. Del mismo modo, si el número de miembros de la relación varía, igualmente ha de variar el numeral con el que se refiere a sí mismo el hablante: “José, Juana y yo" vendría a decirse $\left({ }^{*}\right)$ ”Jose, Juana y los tres" ("Joxe, Joana eta hirurok"), y así sucesivamente.
} 


\section{Las dificultades para aprehender su contenido}

La correspondencia familiar es un diálogo entre miembros de un grupo humano cerrado, que comparte una microhistoria específica y, por lo tanto, comparte un código referencial que no tiene por qué ser el general de la sociedad en la que viven. Éste y otros tipos de documentación personal se basan en unas vivencias grupales compartidas por sus miembros, a partir de los cuales se elaboran unos ámbitos referenciales sobre los que se levanta el discurso. Existen así, por ejemplo, elementos que el historiador podría considerar relevantes, pero que no se verán reflejados en la correspondencia porque no tienen la misma consideración para sus autores, o porque éstos los entienden como parte del contexto, que se dan por sobreentendidos pero no son directamente mencionados.

La mayor dificultad de comprensión estriba, sin embargo, en la carencia de elementos para reconstruir ese contexto. El historiador puede llegar a entender aquellas cuestiones relativas al entorno macrohistórico general en el que se datan los documentos, pero no al microhistórico particular del grupo que genera la correspondencia. Así, es muy habitual que contenidos, dataciones comparadas y referencias, no se hagan siempre respecto a hechos que afectaron a la sociedad en general, sino sobre todo a los particulares hitos históricos del grupo de referencia. Más importancia que el bombardeo de Guernica o la caída de Bilbao durante la Guerra Civil española pueden tener, por poner un ejemplo, los momentos en los que la casa familiar es destruida por las bombas, o la fecha en que se le comunicó a la familia la muerte de tal o cual miembro en el frente.

Incluso puede llegar a constatarse, en ciertos casos, la existencia de un vocabulario propio, en el que determinadas palabras adquieren unas connotaciones particulares, diferentes al sentido primario que un observador ajeno podría dar a la palabra utilizada. Así, por ejemplo, si nos tuviéramos que enfrentar al sentido de una frase expresada por un emigrante vizcaíno en Chile, procedente del mismo conjunto documental antes reseñado, que pedía a su madre desde Santiago que "darás saludos a Ipiña y al Coscor, y visitarás a N.S. Jesucristo para llebarle las 25 pesetas que le debo", muy posiblemente interpretaríamos que nos hallamos ante una evidente muestra de religiosidad, posiblemente una promesa hecha por el emigrante antes de partir ante una devoción cristológica local. Pero en la realidad no hay nada de esto y no podríamos llegarlo a saber si no contáramos con el referente contextual — pro- 
porcionado verbalmente por aquellos que pertenecían al mismo grupo familiar- de que "N.S. Jesucristo" no era sino el irreverente apodo con el que era conocido en su círculo de amistad otro joven de su misma localidad, quien efectivamente había prestado al futuro emigrante la cantidad que ahora solicita que se le devuelva. Ciertamente, lo que se deduce de una misma frase, según contemos o no con la información contextual, es radicalmente diferente.

El caso extremo lo representa un tipo especial y a la vez muy abundante, de fuentes documentales personales, a veces incorporadas a la correspondencia: las fotografías. En este caso, el historiador apenas suele tener problemas para acceder al nivel denotativo del contenido de una imagen (es posible identificar si lo que tenemos delante es, pongamos el caso, una "escena de boda"; e incluso podríamos ser capaces de establecer una datación mediante elementos externos tales como la técnica fotográfica utilizada o el tipo de ropa y peinados que llevan los retratados). Otra cosa es el acceso al nivel connotativo, ese que otorga todo su contenido a la imagen, pero que está plagado de referencias particulares sin las que es imposible la cabal comprensión del documento y de las circunstancias y sentido que se le dio a la imagen cuando se tomó (Manfredi 2005). Una fotografía en la que se presenten, sin más, cuatro hombres mirando a la cámara, puede ser sin embargo el testimonio del reencuentro tras años de separación: esto último sería, sin duda, el contenido principal del documento, pero no es posible percibirlo directamente del mismo, si no podemos conocer el contexto. De aquí la importancia que tiene el uso de mediadores o traductores: personas con acceso al conocimiento del contexto, que pueden complementar sus contenidos mediante explicaciones y comentarios. Lógicamente, tal labor, aun siendo necesaria, se vuelve más laboriosa, hasta acabar por ser imposible según retrocedemos en el tiempo y accedemos a documentos de personas fallecidas largo tiempo atrás, de los que no hay descendientes vivos que puedan recordar y reconstruir los contextos precisos.

\section{CONCLUSIÓN}

En resumen, resulta innegable que los documentos personales, y entre ellos la correspondencia, han adquirido una relevancia creciente durante los últimos años en los estudios migratorios. Entre sus virtudes, se halla la de haber permitido y 
abierto la vía a nuevas interpretaciones, que han contribuido a ampliar la perspectiva de análisis y lo que podemos saber sobre las migraciones. Su uso ha venido de la mano de una renovación metodológica que, aplicada al estudio de las migraciones, nos ha permitido una diversificación de miradas y enfoques sobre el campo de análisis y, por tanto, un mayor complejidad en las conclusiones.

Sin embargo, a pesar del elevado nivel de expectativas con el que fue saludado inicialmente su uso, las fuentes personales no sólo han venido a mostrar sus posibilidades, sino también sus limitaciones. Frente a los excesos que hacían de este tipo de fuentes el arma definitiva por la democratización de la historia, cualquier cosa que esto significara, el uso cada vez más habitual de esta documentación en los análisis historiográficos, el desarrollo de metodologías específicas para su utilización y la sujeción de sus contenidos a la crítica externa e interna propia de la ciencia histórica han venido a situar su uso en una cómoda normalidad. Pero esta misma normalidad de su uso no es sino un signo más de su propia relevancia. 


\section{BIBLIOGRAFÍA}

ÁlVArez Gila, Ó. (1993), “Argentinako 1890 urteko krisialdiaren eragina Euskal Herriko emigrazioaren kontrako kanpainetan”, Muga, 86, pp. 32-45.

- (1995), "La formación de la colectividad inmigrante vasca en los países del Río de la Plata (siglo XIX)", Estudios Migratorios Latinoamericanos, 30, pp. 299-331.

— (1998), "Los exiliados no somos de ningún lugar. Análisis crítico", Studi Emigrazione/Études Migrations, 131, pp. 549-557.

- (2002), “'Cien reales para hacer viaje fuera de esta tierra’: reflexións sobre a lóxica da emigración ultramarina no País Basco (séculos XVIII-XIX)”, Estudos Migratorios, 13-14, pp. 115-43.

- (2006), "Iniciativas educativas de los emigrantes vascos en América: entre la tradición y la adaptación", en Juan José Sánchez Baena y Lucía Provencio (eds.), El Mediterráneo y América, Murcia: Editora Regional de Murcia, 2006, vol. I, pp. 233-49.

Álvarez gila, Ó. y J. M. a TÁpIZ Fernández (1996), "Prensa nacionalista vasca y emigración a América (1900-1936)", Anuario de Estudios Americanos, LIII, pp. 233-60.

Angulo Morales, A. (1995), "Nire Jaun eta Jabe. Aproximación a las formas protocolarias en la correspondencia epistolar del Setecientos", en VV. AA., Actas del Congreso Internacional "A Historia a Debate", Santiago de Compostela: HAD, vol. 2, pp. 159-74.

- (2007), De Cameros a Bilbao. Negocios, familia y nobleza en tiempos de crisis (1770-1834), Bilbao: UPV/EHU.

Aramburu Zudaire, J. M. (2005), “América y los vascos. Una perspectiva historiográfica”, Vasconia, 34, pp. 249-74.

Arroyo, L. (2006), "Redes de influencia: relaciones privilegiadas en el comercio colonial a finales del siglo XVIII: los Marticorena y su correspondencia epistolar”, ponencia presentada en el congreso Redes y prácticas clientelares en el ejercicio del poder: América Latina ayer y hoy. XII Encuentro de Latinoamericanistas Españoles. Santander, 21-23 de septiembre de 2006.

Azcona PAstor, J. M. (1992), Los paraisos posibles. Historia de la emigración vasca a Argentina y Uruguay en el siglo XIX, Bilbao: Universidad de Deusto.

BlÁZquez, A., A. BRUNETON-GOVERnATORI y M. PAPY (2002), "La documentación privada y la emigración: la correspondencia de emigrantes bearneses hacia América", en Ó.Álvarez Gila y A. Angulo Morales (eds.), Las migraciones vascas en perspectiva histórica (siglos XVI-XX), Bilbao: UPV/EHU, 2002, pp. 209-33.

Borderías, C. (1995), "La Historia Oral en España a mediados de los noventa", Historia y Fuente Oral, 13, pp. 113-29.

Cid AbÁsolo, C. (2002), "Las fronteras de la lengua vasca a lo largo de la historia", Revista de Filología Románica, 19, pp. 15-36.

Colá y Goiti, J. (1883), La emigración vasco-navarra, Vitoria: Diputación de Álava.

DíEZ Noci, J. (2001), "Historia del periodismo en lengua vasca de los Estados Unidos: dos semanarios de Los Ángeles en el siglo XIX”, Zer, 10, consultable en http://ehu.es/zer/numero10.htm.

- (2003), Historia del periodismo en lengua vasca, consultado en http://www.ehu.es/diaznoci/inedit/0.htm.

A. GibelLi (1997), "Les témoignages des émigrants entre oralité et écriture", en M. Rouche y C. Maltone (dirs.), Sur le pas des Italiens en Aquitaine au vingtième siècle. Actes du Colloque International Talence-Bordeaux, Burdeos: Maison des Sciences de l'Homme d'Aquitaine, pp. 289-313. 
IÑigo AriZTEGI, A. (2004), "José María Satrustegi: su aportación en el campo lingüístico”, Fontes Linguae Vasconum, 96, pp. 373-80.

Iriani Zalakain, M. (2000), Hacer América. Los vascos en la Pampa húmeda, Argentina (1840-1920), Bilbao: UPV/EHU.

Larrazabal Saitua, O. (2007), "Querido hijo. Cartas de emigrantes entre Chile y País Vasco", EuskonewserMedia, edición electrónica, n. ${ }^{\circ} 379$ y 380, consultable en http://www.euskonews.com/0379zbk/kosmo37901.html.

Macías Domínguez, I. y F. Morales Padrón (1991), Cartas desde América, 1700-1800, Sevilla: Junta de Andalucía.

MANFredi, M. (2005), "Imágenes de la emigración vasca a través de las fotografías públicas y privadas", EuskonewserMedia, 298, consultable en http://www.euskonews.com/0289zbk/kosmo28901.html.

- (2009), Fotografía y emigracion. La fotografía como fuente para el análisis de los procesos migratorios, Vitoria-Gasteiz: Gobierno Vasco.

Martina, Á. de (2004), Santiago Ibarra: Historia de un inmigrante vasco, Vitoria-Gasteiz: Gobierno Vasco.

Martínez de Salinas Alonso, M. a L. (2007), Noticias de Cuba. Cartas de emigrantes vallisoletanos en la segunda mitad del siglo XIX, Valladolid: Instituto Interuniversitario de Estudios de Iberoamérica y Portugal.

Martínez Martínez, M. a Del C. (2007), Desde la otra orilla. Cartas de Indias en el Archivo de la Real Chancillería de Valladolid, León: Universidad de León.

NúŇEZ SEIXAS, X. M. (2000), "Emigración de retorno y cambio social en la Península Ibérica: algunas observaciones teóricas en perspectiva comparada”, Migraciones \& Exilios, 1, pp. 27-66.

- (2001), "Historiografía española reciente sobre migraciones ultramarinas: un balance y algunas perspectivas", Estudios Migratorios Latinoamericanos, 48, pp. 269-96.

- (2002), O inmigrante imaxinario. Estereotipos, representacións e identidades dos galegos na Arxentina (1880-1940), Santiago de Compostela: USC.

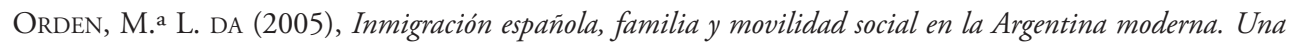
mirada desde Mar del Plata (1890-1930), Buenos Aires: Biblos.

Отте, Е. (1988), Cartas privadas de emigrantes a Indias, 1540-1616, Sevilla: Junta de Andalucía.

Pildain Salazar, M. a P. (1984), Ir a América. La emigracion vasca a América (Guipúzcoa, 1840-1870), San Sebastián: Sociedad Guipuzcoana de Ediciones y Publicaciones, 1984.

SÁNCHEZ RUBio, R. e I. TESTÓN NúNÉEZ (1999), El hilo que nos une. Las relaciones epistolares en el Viejo y el Nuevo Mundo (siglos XVI-XVIII), Cáceres: Editora Regional de Extremadura.

Satrústegui, J. M. ${ }^{a}$ (1979a), "Documentos vascos del año 1664 en un proceso matrimonial de Oyarzun”, Fontes Linguae Vasconum, Pamplona, 33, pp. 529-48.

- (1979b), "Tres cartas vascas del año 1622”, Fontes Linguae Vasconum, 31, pp. 59-70.

Siegrist de Gentile, N. L. (2004), "Vascos propietarios de barcos y su comercio en Buenos Aires: siglos XVIII-XIX”, Euskonews \& Media, 272, consultable en http://www.euskonews.com/0272zbk/kosmo27201.html.

Sierra Blas, V. (2004), "Puentes de papel. Apuntes sobre las escrituras de la emigración", Horizontes Antropológicos, Porto Alegre, 22, DOI: 10.1590/S0104-71832004000200006.

Tesoros (2001): Tesoros de la Real Academia de la Historia. Palacio Real de Madrid, abril-junio 2001, Madrid: RAH. 
Thistlethwaite, F. (1960), "Migration from Europe Overseas in the Nineteenth and Twentieth Centuries", en XI Congrès International des Sciences Historiques. Stockholm, 21-28 Août 1960. Rapports, vol. V: Histoire Contemporaine, Göteborg/Estocolmo/Uppsala: Almquist \& Wiksell, pp. 32-60.

Ugarte, A. (2010), "Los inmigrantes vascos en Argentina a través de las fuentes epistolares. Análisis de un caso”, en Ó. Álvarez Gila (ed.), Organización, identidad e imagen de las colectividades vascas de la emigración (siglos XVI-XXI), Bilbao: UPV/EHU, pp 171-93.

URKIZU, P. (1995), Exiliatuok ez gara inongoak, Vitoria-Gasteiz: Diputación de Araba.

VergarA, J. I. (2004), “¿La voz de los sin voz? Análisis crítico de la producción de testimonios en las ciencias sociales", Aposta. Revista de Ciencias Sociales, 8, consultable en: http://www.apostadigital.com.

VILANOVA, Mercedes (1998), "La historia presente y la historia oral. Relaciones, balance y perspectivas", Cuadernos de Historia Contemporánea, 20, pp. 61-70.

Zaballa Beascoechea, A. de (1999), "Cartas de vascos en México. Vida privada y relaciones de paisanaje”, en A. Garritz (coord.), Los vascos en las regiones de México, siglos XVI a XX, Mexico: UNAM/Eusko Jaurlaritza/ Instituto Vasco-Mexicano de Desarrollo, pp. 83-99. 